\title{
Estrogen-Enhanced Neurite Growth: Evidence for a Selective Induction of Tau and Stable Microtubules
}

\author{
Adriana Ferreira and Alfredo Caceres \\ Instituto de Investigacion Medica Mercedes y Martin Ferreyra, (5000) Cordoba, Argentina
}

\begin{abstract}
Estrogen stimulates the neurite outgrowth response of medial basal hypothalamic neurons maintained in culture. We show here that one effect of estrogen is to promote an increase in $\tau$, but not in tubulin, microtubule-associated protein 1a (MAP-1a), or MAP-2 protein levels. This response precedes and accompanies an increase in stable microtubules and in neurite length. Taken collectively, our data suggest that estrogen-enhanced neurite growth is mediated by a selective induction of microtubule-stabilizing factors, namely, the $\tau$ proteins.
\end{abstract}

During recent years, the importance of gonadal steroids hormones for the growth and differentiation of neurons and their neurites has become increasingly evident. Thus, several in vitro studies have shown that sex steroids are capable of promoting neuronal survival or neurite extension and arborization in explants or dissociated cell cultures from different brain areas (Faivre-Bauman et al., 1981; Loudes et al., 1983; Reisert et al., 1987; Toran-Allerand, 1976a,b, 1981, 1983, 1985, Toran-Allerand et al., 1988; Uchibori and Kawashima, 1985a,b). There is considerable interest in determining the mechanisms underlying these growth-promoting effects of steroids because they may provide some clue for understanding how the sexual dimorphic organization of the brain is brought about (ToranAllerand, 1981, 1985).

Unfortunately, little is known about how these hormones exert their neuritogenic effect or about the elements of the neuron involved in this response. Because microtubule assembly is one of the key events involved in neurite elongation (Mitchison and Kirschner, 1988), it may well be that sex steroids exert their action by modifying and/or enhancing the expression of microtubule-associated proteins (MAPs; Matus, 1988) which are known to promote tubulin polymerization or microtubule stability during active process extension (Greene et al., 1983; Drubin et al., 1985, 1988; Black et al., 1986; Brugg and Matus, 1988; Tucker et al., 1988; Ferreira et al., 1989, 1990). With these considerations in mind, we have chosen to analyze the effect of estrogen upon the growth of neurites and the pattern of expression of several microtubular proteins in dissociated cultures of hypothalamic neurons.

\footnotetext{
Received Dec. 7, 1989; revised Aug. 30, 1990; accepted Sept. 5, 1990.

The authors want to express their gratitude to Dr. L. I. Binder, $\Lambda$. Frankfurter, K. Kosik, A. Matus, and G. Piperno for providing the monoclonal antibodies used in this study. This work was supported by grants from CONICET, CONICOR, and Fundacion Perez Companc to A.C. A.F. is the recipient of an external fellowship from CONICET.

Correspondence should be addressed to Adriana Ferreira, Department of Neuroscience, University of Virginia School of Medicine, Box 230 Medical Center, Charlottesville, VA 22908.

Copyright (C) 1991 Society for Neuroscience $0270-6474 / 91 / 110392-09 \$ 03.00 / 0$
}

\section{Materials and Methods}

Preparation of cell cultures. For preparing dissociated cell cultures of hypothalamic neurons, embryos were removed aseptically from pregnant rats on gestational days 17 (E17) or 19 (E19). The embryos were transferred to dishes containing phosphate-buffered saline (PBS), where the brains were dissected and freed of meninges. Blocks of tissue (approximately $0.5 \mathrm{~mm}$ ) were obtained from a region of the basal hypothalamus, which extended from the caudal edge of the optic chiasm to the rostral edge of the mammilary body, laterally to the hypothalamic sulci and about as deep as $0.5 \mathrm{~mm}$. These pieces of tissue were incubated in a solution containing $0.25 \%$ trypsin for $30 \mathrm{~min}$ at $37^{\circ} \mathrm{C}$, and then they were washed and passed through a constricted Pasteur pipette. The resulting cell suspension was plated onto poly-D-lysine-coated glass coverslips at densities ranging from 5000 to 15,000 cells per $\mathrm{cm}^{2}$. The tissue culture medium employed was Eagle's minimum essential medium supplemented with either $10 \%$ fetal calf serum or the N2 mixture of Bottenstein and Sato (1979). Once every $3 \mathrm{~d}, 1 / 2$ of the culture medium was replaced with fresh medium. In all cultures maintained with serumsupplemented medium, cytosine arabinoside $(50 \mu \mathrm{M})$ was added to the culture medium to avoid the growth of non-neuronal cells. In this regard, it is worth mentioning that double immunofluorescence labeling of hypothalamic cell cultures with neuron-specific (MAP-2 or class III $\beta$-tubulin) or glial-specific [glial fibrillary acidic protein (GFAP)] antibodies revealed that more than $95 \%$ of the cells were MAP-2 positive $(+$; or class III $\beta$-tubulin + ) and GFAP negative $(-)$, while about $3 \%$ were MAP-2/GFAP + . Treatment of the cultures with steroid hormones (see below) did not alter the proportion of neuronal versus non-neuronal cells, at least during the first week in culture, the time period used in the present study.

Experimental cultures were treated with estradiol 17- $\beta$, estradiol $17-$ $\alpha$, or estrone (final concentration in the culture medium was $0.1 \mu \mathrm{M}$ ). The steroids were dissolved in ethanol at a concentration of $100 \mu \mathrm{g} / 50$ $\mu \mathrm{l} ; 5 \mu \mathrm{l}$ of this solution was then added to $100 \mathrm{ml}$ of tissue culture medium; control, nontreated cultures received an equal amount of ethanol. For some experiments, culture medium was replaced with fresh medium containing $10 \mu \mathrm{M}$ colchicine; cells were then maintained in this medium for 3 or $6 \mathrm{hr}$. The microtubules remaining in the Triton $\mathrm{X}$-100-insoluble fraction from cultures treated with this depolymerizing agent are referred to as colchicine-resistant microtubules (see also Ferreira et al., 1989, 1990).

Microtubule protein level determination, morphometric analysis, and immunocytochemistry. Cytosolic or detergent-extracted cytoskeletal fractions from cell cultures were prepared as described by Ferreira et al. (1989), and the levels of several microtubular proteins (tubulin, acetylated $\alpha$-tubulin, MAP-1a, MAP-2, and $\tau$ ) were determined by dot immunobinding (Caceres et al., 1988) with monoclonal antibodies that have been extensively characterized. They included the following: (1) tubulin antibodies against all isoforms of $\alpha$-tubulin (clone DM1A; Blose et al., 1984) or $\beta$-tubulin (clone Tu9B; Caceres et al., 1984), the clone Tu-J1 against the Class III neuron-specific $\beta$-tubulin isoform (Moody et al., 1989), and the clone 6-11B1 against the acetylated isoform of $\alpha$-tubulin (Piperno et al., 1987); (2) MAP-2 antibodies against different nonphosphorylated epitopes of this molecule (clones AP-9 and AP-14 Caceres et al., 1984); and (3) $\tau$ monoclonal antibodies against nonphosphorylated epitopes of these molecules (clones Tall-1 and 5 E2; Binder et al., 1985; Kosik and Finch, 1987; Dotti et al., 1987; Ferreira et al., 1989, 1990; Caceres and Kosik, 1990). Standard curves were constructed, and the amount of each of the proteins analyzed in unknown samples was determined by extrapolation of the linear regions 
Table 1. Effect of estradiol 17- $\beta(100 \mathrm{ng} / \mathrm{ml})$ on total neuritic, axonal, and dendritic length ${ }^{\alpha}$ of hypothalamic neurons maintained in culture with serum-supplemented medium

\begin{tabular}{|c|c|c|c|c|c|c|c|}
\hline \multirow[b]{2}{*}{ DIV } & & \multicolumn{3}{|l|}{ E17 } & \multicolumn{3}{|l|}{ E19 } \\
\hline & & Nontreated & $\begin{array}{l}\text { Estradiol } \\
17-\alpha\end{array}$ & $\begin{array}{l}\text { Estradiol } \\
17-\beta\end{array}$ & Nontreated & $\begin{array}{l}\text { Estradiol } \\
17-\alpha\end{array}$ & $\begin{array}{l}\text { Estradiol } \\
17-\beta\end{array}$ \\
\hline \multirow[t]{3}{*}{3} & Axons & $50.1 \pm 5$ & $48.5 \pm 8$ & $59.4 \pm 5$ & $68.4 \pm 4$ & $74.2 \pm 8$ & $132.8 \pm 7$ \\
\hline & Dendrites & $12.5 \pm 2$ & $10.2 \pm 2$ & $14.2 \pm 2$ & $28.1 \pm 2$ & $26.4 \pm 4$ & $38.8 \pm 8$ \\
\hline & Total & $62.0 \pm 6$ & $58.4 \pm 4$ & $72.3 \pm 8$ & $86.5 \pm 5$ & $92.6 \pm 6$ & $164.8 \pm 8$ \\
\hline \multirow[t]{3}{*}{5} & Axons & $215.3 \pm 10$ & $200.2 \pm 12$ & $315.2 \pm 25$ & $260.4 \pm 12$ & $264.2 \pm 14$ & $415.6 \pm 14$ \\
\hline & Dendrites & $43.2 \pm 6$ & $40.2 \pm 8$ & $90.4 \pm 14$ & $65.6 \pm 8$ & $60.2 \pm 8$ & $105.2 \pm 8$ \\
\hline & Total & $267.0 \pm 12$ & $242.2 \pm 16$ & $402.8 \pm 30$ & $328.8 \pm 12$ & $330.4 \pm 12$ & $525.8 \pm 22$ \\
\hline \multirow[t]{3}{*}{7} & Axons & $328.1 \pm 17$ & $330.4 \pm 22$ & $515.6 \pm 15$ & $540.5 \pm 14$ & $520.4 \pm 25$ & $735.4 \pm 21$ \\
\hline & Dendrites & $92.4 \pm 14$ & $80.2 \pm 8$ & $145.8 \pm 11$ & $140.8 \pm 12$ & $120.6 \pm 10$ & $225.5 \pm 18$ \\
\hline & Total & $412.4 \pm 28$ & $402.2 \pm 14$ & $629.3 \pm 25$ & $670.6 \pm 20$ & $635.5 \pm 20$ & $925.9 \pm 35$ \\
\hline
\end{tabular}

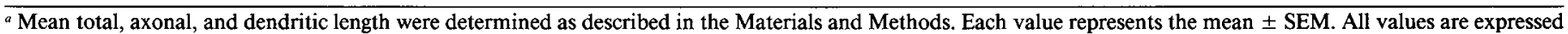
in $\mu \mathrm{m}$. A total of 50 cells was measured for each time point and experimental condition.

of the unknown to the linear portions of the standard. Also, the relative amount of the microtubular proteins was determined by scanning antibody-stained Western blots of cytosolic fractions as described previously (Ferreira et al., 1989).

Mean total axonal and dendritic length of individual neurons was quantified on camera lucida drawings using an Apple digitizer (Apple Computer Inc.). A total of 50 cells was measured for each time point of an experimental condition; statistical comparisons were made using appropriate 2-way analysis of variance (ANOVA). Immunocytochemistry of cell cultures was performed as previously described (Caceres et al., 1986; Ferreira et al., 1987, 1989).

\section{Results}

Neuroblasts of the E17 medial basal hypothalamus maintained in culture display a sequence of morphological changes that result in the establishment of differentiated axonal and dendritic domains. Within a day after plating, these cells display short and thin neurites (3-5 per cell), which taper with distance. A similar morphology is observed after $3 \mathrm{~d}$ in vitro (DIV), with the exception that one of the neurites is several times longer than the others (Fig. 1); the morphological characteristics of this type of neurite resemble those described for axonal processes in both hippocampal (Barlett and Banker, 1984; Caceres et al., 1986; Dotti et al., 1987) and cerebellar cell cultures (Ferreira and Caceres, 1989; Ferreira ct al., 1989). The remaining neurites acquire morphological characteristics of dendrites; thus, they usually branch in $\mathrm{Y}$ angles, taper with distance, and grow at a much slower rate than the axons (Table 1). Besides, dendrites, as opposed to axons, remain immunoreactive for MAP-2 throughout the course of neuronal development in vitro (data not shown; see also Ferreira et al., 1987). A similar morphogenetic pattern is observed in neuroblasts obtained from the E19 hypothalamus; the main difference is that these neurons grow at a faster rate than E17 neurons (Table 1).

The addition of estradiol $17-\beta$ to the culture medium results in a significant increase in axonal and dendritic length with respect to that observed in control, nontreated cells (Tablc 1). On the other hand, no such effect is observed after the administration of estradiol 17- $\alpha$ (Table 1) or estrone (data not shown). In estradiol 17- $\beta$-treated hypothalamic neurons, the increase in neurite length becomes evident after 3 DIV for cultures prepared from the E19 hypothalamus or 5 DIV in the case of E17 ones; it occurs independent of the tissue culture medium employed. Our results also show that this phenomenon is not only the consequence of an increase in the linear length of a given neurite, but also reflects an increase in the number of neurite branches per cell (Table 2); however, it should be noted that the number of primary neurites that hypothalamic neurons extend is not modified by the administration of this hormone.

In control cells, polymeric tubulin, as determined with monoclonal antibodies that recognize all isotypes (clones DMlA or Tu9B), increases significantly and in parallel with axonal and dendritic length; a 2-3-fold increase in total tubulin levels is also detected in these neurons (Table 3). Acetylated or colchicine-resistant microtubules begin to increase after the cells have developed in vitro for $3 \mathrm{~d}$; after that time, microtubule mass and stable microtubules increase in parallel (Table 3; see also Fig. 2). A significant induction in high-molecular-weight MAPs

Table 2. Effect of steroid hormones on the number of segments ${ }^{a}$ of hypothalamic neurons maintained in culture for $5 \mathrm{~d}$ in serum-free medium

Number of neurite segments ${ }^{b}$

\begin{tabular}{lllll}
\multicolumn{2}{l}{ Number of neurite segments } \\
\cline { 2 - 5 } Treatment & Total & 1st order & 2d order & $\begin{array}{l}\text { 3d and 4th } \\
\text { order }\end{array}$ \\
\hline Control & $11.1 \pm 0.4$ & $3.9 \pm 0.2$ & $3.1 \pm 0.1$ & $3.6 \pm 0.4$ \\
Estradiol $17-\alpha$ & $11.8 \pm 0.4$ & $3.8 \pm 0.3$ & $3.2 \pm 0.3$ & $3.4 \pm 0.6$ \\
Estradiol 17- $\beta$ & $17.4 \pm 0.8$ & $4.0 \pm 0.2$ & $4.9 \pm 0.2$ & $7.9 \pm 0.6$ \\
\hline Neurite segment refers to a neurite branch & & &
\end{tabular}

${ }^{a}$ Neurite segment refers to a neurite branch.

${ }^{b}$ Each value represents the mean \pm SEM. A total of 100 cells were analyzed for each experimental condition. 

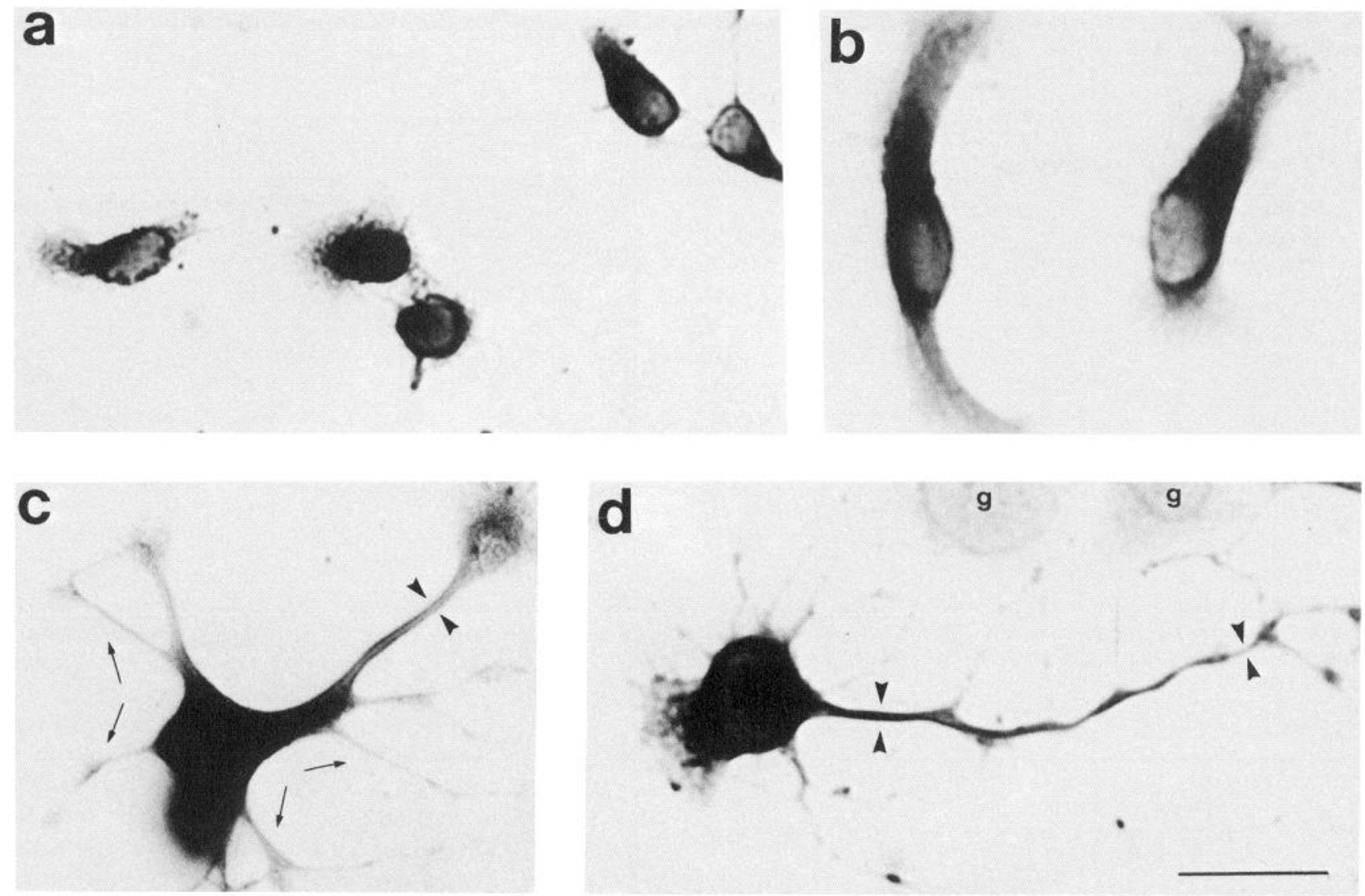

Figure 1. In vitro development of dissociated medial basal hypothalamic neurons obtained from E17 rat embryos as revealed by immunostaining with monoclonal antibody against class III neuron-specific $\beta$-tubulin isotype (clone Tu-J1; Moody et al., 1989). $a$ and $b$, Cells after development in culture for $12 \mathrm{hr}$; at this stage, many cells extend flattened expansions of the cytoplasm that resemble lamellipodia. $c$, Light micrograph showing a hypothalamic neuron after development in culture for $48 \mathrm{hr}$. At this stage, the cells extend several short and thin neurites (arrows); usually, one of them exceeds the others in length (arrowheads), ending in a prominent growth cone. With subsequent development in vitro, this neurite acquires morphological characteristics of axons. An example of such a cell is shown in $d$; note also the absence of staining of glial cells $(g)$ with the monoclonal antibody Tu-J1. Scale bar, $20 \mu \mathrm{m}$.

(HMW-MAPs) is also observed during the in vitro development of hypothalamic neurons; the time course of these inductions is identical to that of the increase in polymeric tubulin and neurite length. $\tau$ protein levels also increase but with a time course similar to that of the induction of stable microtubules (colchicine-resistant and/or acetylated microtubules); besides, $\tau$ binds preferentially to colchicine-resistant cytoskeletons as op- posed to the other MAPs that are initially lost after colchicine treatment (Table 3).

Estradiol $17-\beta$-treated neurons exhibit a similar profile; however, the addition of this steroid, but not estradiol 17- $\alpha$ or estrone, to the culture medium results in a 3 -fold increase in the levels of $\tau$ proteins over the ones observed in control cells (Table 3, Figs. 2, 3). In cultures prepared from the E17 hypothalamus,
Figure 2. Quantitative evaluation of changes in $\tau$ protein levels, microtubule mass, and stable microtubules in E17 estrogen-treated hypothalamic cultures. A, Triangles, estradiol 17- $\beta$-treated cells; circles, estradiol 17- $\alpha$-treated cells. $B$, Triangles, polymeric tubulin in estradiol 17- $\beta$-treated cells; open circles, polymeric tubulin in estradiol $17-\beta$-treated cells; solid circles, colchicine-resistant microtubules in estradiol 17 - $\beta$-treated cells; squares, colchicineresistant microtubules in estradiol 17$\alpha$-treated cells. $t u b$, tubulin. Microtubule protein levels determined by dot immunobinding assay are expressed in microgram per milligram of total cellular protein; each value is the mean \pm SEM.
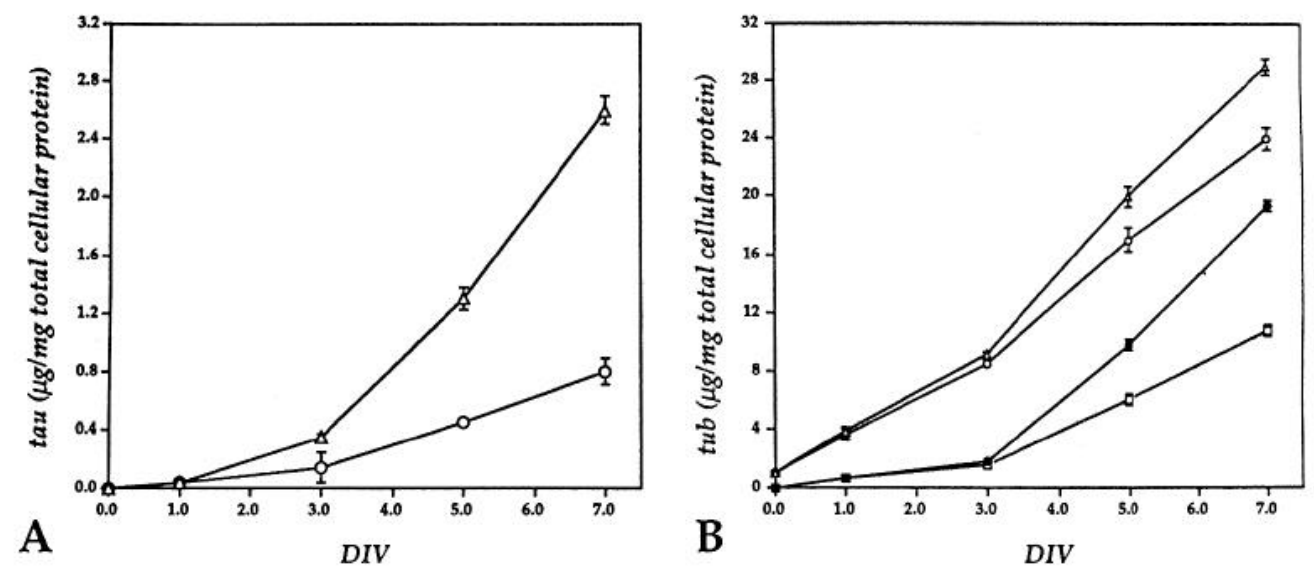
Table 3. Variations in tubulin, MAP-1a, MAP-2, and $\tau$ protein levels ${ }^{\alpha}$ during the in vitro development of hypothalamic neurons ${ }^{b}$ in the presence or absence of estradiol 17- $\beta$

\begin{tabular}{|c|c|c|c|c|}
\hline & \multicolumn{4}{|c|}{ Time after plating (DIV) ${ }^{c}$} \\
\hline & 1 & 3 & 5 & 7 \\
\hline \multicolumn{5}{|l|}{ Tubulin } \\
\hline \multicolumn{5}{|l|}{ Control cells } \\
\hline Cytosolic fraction & $24.4 \pm 0.40$ & $43.0 \pm 0.4$ & $56.5 \pm 1.2$ & $60.0 \pm 1.2$ \\
\hline Cytoskeletal fraction & $3.8 \pm 0.02$ & $8.8 \pm 0.2$ & $18.0 \pm 0.9$ & $24.0 \pm 0.8$ \\
\hline Cytoskeletal fraction CR & $0.7 \pm 0.00$ & $1.6 \pm 0.1$ & $6.0 \pm 0.2$ & $10.8 \pm 0.3$ \\
\hline \multicolumn{5}{|l|}{ Estrogen-treated cells } \\
\hline Cytosolic fraction & $24.8 \pm 0.30$ & $44.4 \pm 0.3$ & $56.0 \pm 0.9$ & $61.0 \pm 0.8$ \\
\hline Cytoskeletal fraction & $3.8 \pm 0.03$ & $9.1 \pm 0.4$ & $20.0 \pm 0.7$ & $29.0 \pm 0.8$ \\
\hline Cytoskeletal fraction CR & $0.7 \pm 0.00$ & $1.8 \pm 0.1$ & $9.8 \pm 0.4$ & $19.4 \pm 0.3$ \\
\hline \multicolumn{5}{|l|}{ MAP-1a } \\
\hline \multicolumn{5}{|l|}{ Control cells } \\
\hline Cytosolic fraction & $0.2 \pm 0.04$ & $0.40 \pm 0.04$ & $1.2 \pm 0.10$ & $2.3 \pm 0.3$ \\
\hline Cytoskeletal fraction & $0.1 \pm 0.01$ & $0.30 \pm 0.01$ & $0.9 \pm 0.05$ & $1.8 \pm 0.1$ \\
\hline Cytoskeletal fraction CR & - & $0.05 \pm 0.01$ & $0.3 \pm 0.01$ & $1.0 \pm 0.1$ \\
\hline \multicolumn{5}{|l|}{ Estrogen-treated cells } \\
\hline Cytosolic fraction & $0.2 \pm 0.03$ & $0.40 \pm 0.02$ & $1.2 \pm 0.30$ & $2.3 \pm 0.2$ \\
\hline Cytoskeletal fraction & $0.1 \pm 0.01$ & $0.30 \pm 0.01$ & $0.8 \pm 0.04$ & $2.1 \pm 0.1$ \\
\hline Cytoskeletal fraction CR & - & $0.05 \pm 0.01$ & $0.3 \pm 0.01$ & $1.2 \pm 0.1$ \\
\hline \multicolumn{5}{|l|}{ MAP-2 } \\
\hline \multicolumn{5}{|l|}{ Control cells } \\
\hline Cytosolic fraction & $0.55 \pm 0.06$ & $2.5 \pm 0.10$ & $3.5 \pm 0.25$ & $6.0 \pm 0.25$ \\
\hline Cytoskeletal fraction & $0.25 \pm 0.01$ & $2.0 \pm 0.08$ & $3.0 \pm 0.15$ & $4.8 \pm 0.15$ \\
\hline Cytoskeletal fraction CR & $0.02 \pm 0.00$ & $0.2 \pm 0.01$ & $1.0 \pm 0.05$ & $2.0 \pm 0.10$ \\
\hline \multicolumn{5}{|l|}{ Estrogen-treated cells } \\
\hline Cytosolic fraction & $0.50 \pm 0.05$ & $2.5 \pm 0.15$ & $3.5 \pm 0.20$ & $6.2 \pm 0.25$ \\
\hline Cytoskeletal fraction & $0.20 \pm 0.01$ & $2.0 \pm 0.10$ & $3.2 \pm 0.12$ & $5.5 \pm 0.10$ \\
\hline Cytoskeletal fraction CR & $0.02 \pm 0.00$ & $0.2 \pm 0.01$ & $1.2 \pm 0.04$ & $2.5 \pm 0.09$ \\
\hline \multicolumn{5}{|l|}{$\tau$} \\
\hline \multicolumn{5}{|l|}{ Control cells } \\
\hline Cytosolic fraction & $0.04 \pm 0.00$ & $0.14 \pm 0.01$ & $0.45 \pm 0.03$ & $0.82 \pm 0.09$ \\
\hline Cytoskeletal fraction & $0.02 \pm 0.00$ & $0.07 \pm 0.01$ & $0.27 \pm 0.02$ & $0.70 \pm 0.08$ \\
\hline Cytoskeletal fraction CR & $0.01 \pm 0.00$ & $0.05 \pm 0.00$ & $0.20 \pm 0.01$ & $0.65 \pm 0.03$ \\
\hline \multicolumn{5}{|l|}{ Estrogen-treated cells } \\
\hline Cytosolic fraction & $0.04 \pm 0.00$ & $0.35 \pm 0.01$ & $1.30 \pm 0.08$ & $2.60 \pm 0.03$ \\
\hline Cytoskeletal fraction & $0.02 \pm 0.00$ & $0.20 \pm 0.01$ & $0.80 \pm 0.04$ & $2.00 \pm 0.03$ \\
\hline Cytoskeletal fraction CR & $0.01 \pm 0.00$ & $0.18 \pm 0.00$ & $0.70 \pm 0.04$ & $2.00 \pm 0.04$ \\
\hline
\end{tabular}

$\overline{\mathrm{CR}}$, colchicine-resistant.

${ }^{a}$ Tubulin, MAP-1a, MAP-2, and $\tau$ protein levels were determined by quantitative dot immunobinding using ${ }^{125}$ I protein $A$, as described in Materials and Methods.

${ }^{b}$ Hypothalamic cultures were prepared from E17 fetuses.

'Each value represents the mean \pm SEM from measurements of 5 hypothalamic cultures grown on 16-mm Aclar coverslips. Values are expressed in micrograms per milligram of total cellular protein.

the enhanced $\tau$ induction begins at 3 DIV, and further increases are detected at 5 and 7 DIV. By 5 DIV, the levels of colchicineresistant (Table 3, Fig. 2) or acetylated microtubules (data not shown) of estradiol 17- $\beta$-treated hypothalamic neurons are significantly higher than in control ones; an increase in polymeric tubulin is also evident at 7 DIV. $\tau$ protein levels and stable microtubules also increase above control levels in estrogentreated cells of E19 hypothalamic cultures; the time course of this increase occurs earlier than in E17 neurons.

In order to obtain further evidence of the effect of estrogen upon $\tau$ induction, Western blot analyses were performed in cytosolic extracts obtained from control and treated cultures of different ages. Hypothalamic neurons in vitro express a Tau-1 immunoreactive polypeptide at $M_{r} 58,000$, which migrates in a similar position to that of $\tau b$ from adult rat brain cytosolic fractions or microtubules (see Fig. 3). Cultures treated with estradiol 17- $\beta$ display a similar pattern of $\tau$ polypeptides with the difference that the expressed $\tau$ isoform increases significantly with respect to the levels detected in control, nontreated cells and/or cells treated with estradiol 17- $\alpha$. Densitometric analysis of Western blots shows a 3-fold increase in $\tau$ protein levels in estradiol 17- $\beta$-treated hypothalamic cultures with respect to the values observed in control cultures; this increase is similar to that determined by dot immunobinding assay.

An enhanced induction of $\tau$ and stable microtubules, as well as an increase in neurite length, is also detected when the steroid 

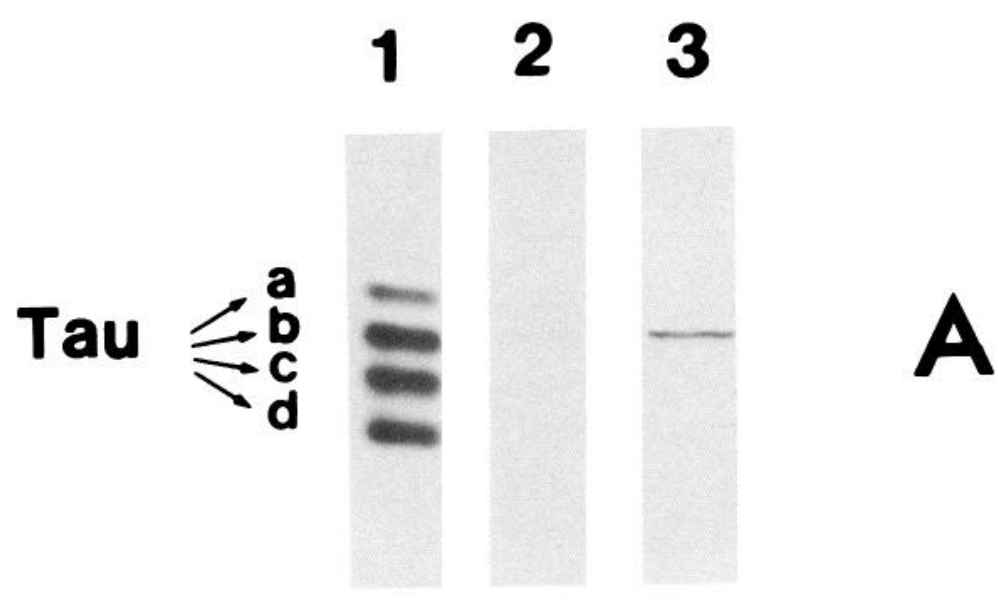

Figure 3. (A) and class III $\beta$-tubulin $(B)$ protein levels in cytosolic fractions of E17 hypothalamic neurons maintained in culture for $5 \mathrm{~d}$ as revealed by Western blots with Tau-1 and Tu-J1 monoclonal antibodies. Lanes 1, Tau1 -immunoreactive polypeptides from adult rat brain microtubules; lanes 2 , estradiol 17- $\alpha$-treated culture; lane 3 , estradiol $17-\beta$-treated culture. Forty $\mu \mathrm{g}$ of protein was loaded in lanes in $A$, and $20 \mu \mathrm{g}$ in lanes in $B$.

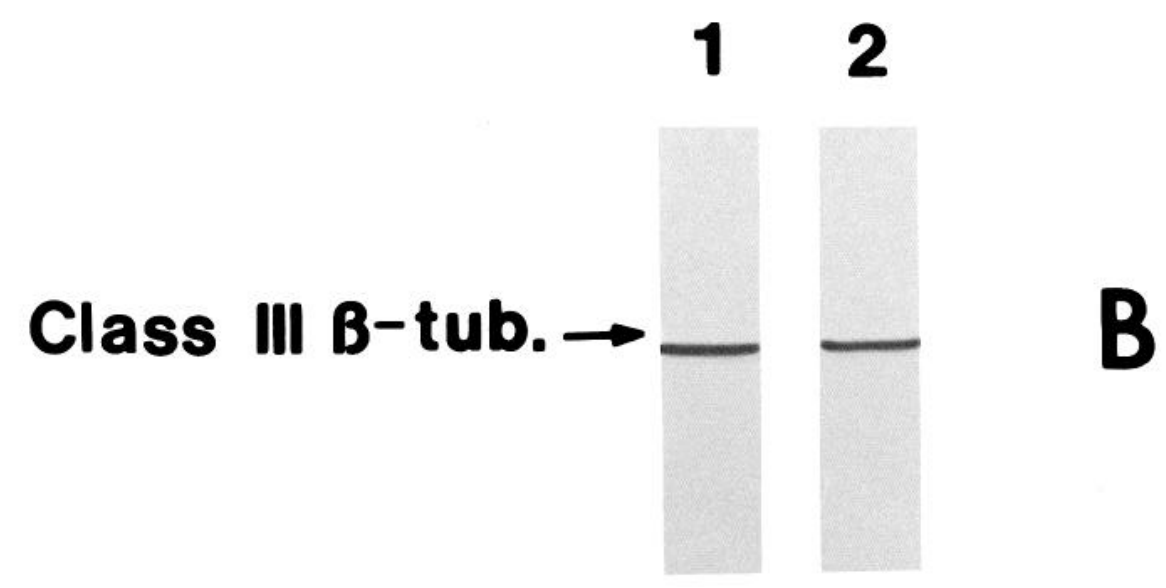

is added to already differentiated hypothalamic neurons (4-DIV cultures; see Table 4). On the other hand, the levels of total tubulin, MAP-1a, and MAP-2 do not increase above those observed in control cells after the addition of estradiol $17-\beta$; this phenomenon was observed under all the experimental conditions in which the steroid was added to the culture medium. However, an increase in the amount of MAP-1a or MAP-2 bound to the cytoskeleton was evident at 7 DIV (see Table 2).

Finally, in order to determine if the enhanced $\tau$ induction observed in estradiol 17- $\beta$-treated cells was related with a preferential survival of specific classes of neurons containing higher $\tau$ levels than others, cell cultures were stained with 2 monoclonal antibodies against $\tau$ proteins (clones Tau-1 and 5B2; Caceres and Kosik, 1990). As expected, $\tau$ immunoreactivity was detected in both the control and the estrogen-treated hypothalamic neurons; however, no differences in the intensity of staining were observed among the neurons present within each of these experimental groups. This phenomenon was observed independent of the type of fixation (methanol vs. aldehyde fixation), detection method employed (immunoperoxidase vs. immunofluorescence), or concentration of the primary antibody. On the other hand, the majority of the neurons present in estradiol 17 $\beta$-treated cultures displayed an increase in $\tau$ and acetylated $\alpha$-tubulin immunoreactivity when compared with the control, nontreated cultures (Fig. 4).

\section{Discussion}

The present study provides evidence that supports and extends previous observations indicating that epigenetic factors have a key role as regulators of the expression of MAPs in developing neurons (Drubin et al., 1983, 1985, 1988; Ferreira et al., 1987, 1989, 1990). Prior to evaluating these results, an analysis of the pattern of expression of MAPs in control hypothalamic neurons seems pertinent. In these cells, axonal and dendritic growth are preceded and accompanied by a significant induction of neuronspecific MAPs. The time course of their increase is similar to that reported for other brain neurons maintained in vitro (Couchie et al., 1986; Cambray-Deakin et al., 1987; Ferreira et al., 

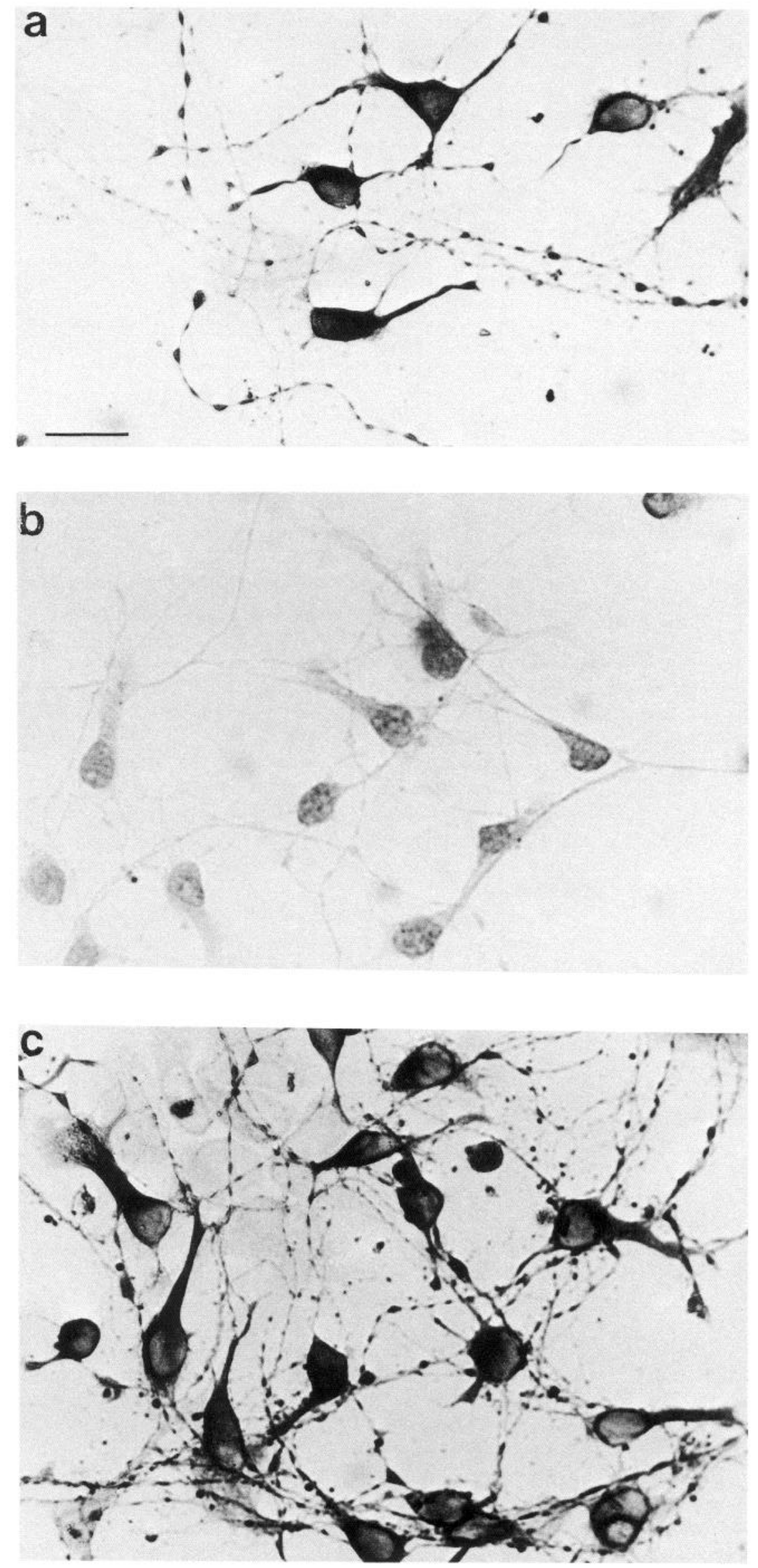

Figure 4. a, Light micrograph showing the pattern of immunostaining of medial basal hypothalamic neurons after development in vitro for $5 \mathrm{~d}$ as revealed by immunocytochemistry with the monoclonal antibody Tau- 1 diluted $1: 50$. As previously reported for other neurons that develop in culture (Dotti et al., 1987; Ferreira et al., 1987) immunoreactivity is found in both axons and dendrites. $b$, Cells from a sister culture to that shown in $a$ stained with Tau-1 diluted 1:500; note the faint staining of neuritic processes. $c$, Light micrograph of estrogen-treated hypothalamic neurons after development in vitro for $5 \mathrm{~d}$. The cells were immunostained with Tau-1 diluted 1:500; note the dramatic increase in $\tau$ immunoreactivity when compared with the pattern displayed by the cells shown in $b$. Scale bar, $50 \mu \mathrm{m}$. 
Table 4. Changes in total neuritic length, $\tau$ protein levels, and acetylated $\alpha$-tubulin levels after the addition of estradiol 17- $\beta$ to differentiated hypothalamic cell cultures ${ }^{a}$

\begin{tabular}{|c|c|c|c|c|}
\hline $\begin{array}{l}\text { Days } \\
\text { after } \\
\text { plating }\end{array}$ & Treatment & $\begin{array}{l}\text { Total neuritic } \\
\text { length } \\
\text { (mean } \pm \mathrm{SEM})^{b}\end{array}$ & $\begin{array}{l}\tau \text { Protein levels } \\
(\text { mean } \pm \text { SEM })^{c}\end{array}$ & $\begin{array}{l}\text { Acetylated } \\
\alpha \text {-tubulin } \\
\text { levels }^{d}\end{array}$ \\
\hline 4 & Control & $165 \pm 10$ & $0.34 \pm 0.02$ & $5.4(0.94)$ \\
\hline 7 & + Alcohol on day 4 & $425+15$ & $0.80+0.05$ & $14.8(0.99)$ \\
\hline 7 & $\begin{array}{r}+ \text { Estradiol } 17-\beta \text { on } \\
\text { day } 4(100 \mathrm{ng} / \mathrm{ml})\end{array}$ & $715 \pm 20$ & $2.20 \pm 0.40$ & $25.3(0.98)$ \\
\hline
\end{tabular}

\footnotetext{
${ }^{a}$ Cell cultures were prepared from E17 rat embryos.

${ }^{b}$ Values are expressed in $\mu \mathrm{m}$.

$c \tau$ protein levels, expressed in micrograms per milligram of total cellular protein, were determined by dot immunobinding.

${ }^{d}$ Acetylated $\alpha$-tubulin levels were determined by dot immunobinding as described by Piperno et al. (1987). The numbers are expressed in cpm per microgram. They represent the slopes of regression lines; the numbers in parentheses are the corresponding coefficients of determination.
}

1989). Thus, HMW-MAPs display a pattern of expression that is highly coincident with the increase in total polymeric tubulin, while $\tau$ proteins display one coincident with that of stable microtubules. These observations are consistent with the idea that MAP-la and/or MAP-2 are important factors involved in promoting microtubule assembly, and that $\tau$ proteins are important in determining stability (Drubin et al., 1983, 1985, 1988; Matus, 1988; Ferreira et al., 1989, 1990). Besides, and as in the case of cerebellar macroneurons that develop in culture or neuronal tumor cell lines, total tubulin levels only increase slightly, a phenomenon that supports the idea that tubulin itself is not a limiting factor for regulating the formation of microtubules during nerve process extension (Drubin et al., 1985; Black ct al., 1986; Ferreira et al., 1989).

It is likely, then, that any substance that enhances the expression of MAPs may, in turn, increase the ability of the neuron to produce more microtubules and, hence, to grow longer and/ or more stable neurites; the dramatic and selective induction of MAP-2 observed during ganglioside-enhanced neurite growth clearly illustrates such a proposal (Ferreira et al., 1990). The present results suggest that at least some of the neuritogenic effect of estrogen is mediated by a similar mechanism. Thus, our observations show that when estrogen enhances neurite growth, this hormone selectively increases $\tau$ protein levels and, afterwards, stable microtubules.

This response seems not to be related to an overall increase in the expression of microtubular proteins, because no effects were observed in total tubulin levels or in the magnitude and time course of the HMW-MAP inductions; nor is it the consequence of an increased rate of growth or stability of estrogentreated neurons, because the enhanced $\tau$ induction precedes the increase in axonal and dendritic length that is observed with respect to control, nontreated cells. Our results also suggest that this effect is not related to an enhanced survival of some type of neuron normally expressing high $\tau$ levels, because the immunocytochemical analysis revealed identical levels of immunoreactivity within each of the experimental cell groups analyzed; besides, the enhanced $\tau$ induction is also detected when estrogen is added to well-differentiated hypothalamic cultures. Also, it is worth mentioning that this effect was observed under serum deprivation, where no glial cell proliferation occurs, ruling out the possibility that differential survival of neurons versus non-neuronal cells could have effects on levels of MAPs measured on a per protein basis.

The enhanced $\tau$ induction in estradiol $17-\beta$-treated cells is followed by an increase in stable microtubules; it is likely that both of these events are correlated, because $\tau$ proteins are preferentially associated with them (Ferreira and Caceres, 1989; Ferreira et al., 1989, 1990), and previous observations have shown that these proteins are capable of stabilizing microtubules in vivo (Drubin and Kirschner, 1986).

The question that now arises concerns the relationship between these inductions and the reported increase in neurite length. One possibility is that this phenomenon simply reflects the existence of more stable neurites that, in response to fixation and/ or other experimental conditions, retract less than control, nontreated ones.

However, the alternative and most likely explanation is that, as a consequence of the expression of more stable microtubules, hypothalamic neurons are able to extend longer neurites with increased stability or to stabilize neurite branches that otherwise would retract. The increase in microtubule mass that accompanies the enhanced induction of stable microtubules supports this idea. Besides, this view is consistent with recent studies showing that, during early neuronal development in vitro, the phase of rapid neuritic elongation is marked by the appearance of a subset of stable microtubules and $\tau$ associated with them (Ferreira and Caceres, 1989; Ferreira et al., 1989), and that axonal elongation and the expression of stable microtubules is selectively blocked by antisense oligonucleotides directed against the $\tau$ mRNA (Caceres and Kosik, 1990). It is also in accordance with the proposal made by Kirschner and Mitchison (1986) suggesting that the expression of stable microtubules is critical for generating and maintaining cell asymmetries and with observations showing that neurons exhibiting a rapid increase in stable microtubules also have an enhanced rate of neurite growth (Cambray-Deakin et al., 1987; Burgoyne and Cambray-Deakin, 1988). It will now be of interest to determine if sex-related differences exist in the quantity and quality of brain microtubules. In this regard, it is worth noting that both developmental and androgen-induced changes in mRNAs coding for specific brain proteins, including tubulinlike molecules, have been identified in the hypothalamic preoptic area (Stanley and Fink, 1986; Stanley et al., 1986). 
Finally, the fact that we detected an increase in $\tau$ and acetylated $\alpha$-tubulin immunoreactivity in the majority of the neurons present in the culture poses intriguing questions about the cellular and molecular mechanisms involved in these inductions. The questions about cellular and molecular mechanisms primarily relate to further data regarding the levels of receptor- or nonreceptor-containing, estrogen-responsive neurons in the type of culture we have employed. In this regard, one may consider the possibility that all cells express estrogen receptors, and hence, they directly respond to the hormone; alternatively, it may well be that estrogen exerts its effect acting on a small population of receptor-containing cells, which, in turn, produces and releases growth-promoting factors capable of enhancing the neuritogenic response of the entire cell population (see Toran-Allerand et al., 1988 , for a further discussion of this issuc). Future studics should distinguish between these and related possibilities.

\section{References}

Barlett WP, Banker G (1984) An electron microscopic study of the development of axons and dendrites by hippocampal neurons in culture: cells which develop without intercellular contacts. J Neurosci 4: 1944-1953.

Binder LI, Frankfurter A, Rebhun LI (1985) The distribution of Tau in the mammalian central nervous system. J Cell Biol 101:13711378.

Black M, Aletta JM, Greene LA (1986) Regulation of microtubule composition and stability during nerve growth factor promoted neurite outgrowth. J Cell Biol 103:545-557.

Blose SD, Meltzer DI, Feranisco JR (1984) Ten nm filaments are induced to collapse in living cells microinjected with monoclonal and polyclonal antibodies against tubulin. J Cell Biol 98:847-858.

Bottenstein JE, Sato GH (1979) Growth of a rat neuroblastoma cell line in serum free supplemented medium. Proc Natl Acad Sci USA 76:514-519.

Brugg B, Matus A (1988) PC12 cells express juvenile microtubuleassociated proteins during nerve growth factor-induced neurite outgrowth. J Cell Biol 107:643-650.

Burgoyne RD, Cambray-Deakin M (1988) The cellular neurobiology of neuronal development: the cerebellar granule cell. Brain Res Rev 13:77-101.

Caceres A, Kosik K (1990) Inhibition of neurite elongation and polarity by Tau antisense oligonucleotides. Nature 343:461-463.

Caceres A, Binder LI, Payne M, Bender P, Rebhun LI, Steward O (1984) Differential subcellular localization of tubulin and the microtubuleassociated protein MAP-2 in brain tissue as revealed by immunocytochemistry with monoclonal hybridoma antibodies. J Neurosci 4: 394-410.

Caceres A, Banker G, Binder L (1986) Immunocytochemical localization of tubulin and the microtubule-associated protein 2 during the development of hippocampal neurons in culture. J Neurosci 6: 714-722.

Caceres A, Busciglio J, Ferreira A, Steward O (1988) An immunocytochemical study of the microtubule-associate protein MAP-2 during post-lesion dendritic remodeling in the central nervous system of adult rats. Mol Brain Res 3:233-246.

Cambray-Deakin M, Morgan A, Burgoyne RD (1987) Sequential appearance of cytoskeletal components during the early stages of neurite outgrowth from cerebellar granule cells in vitro. Dev Brain Res 37: 197-207.

Couchie D, Faivre-Bauman A, Puymirat J, Guillemiot J, Tixier-Vidal A, Nunez J (1986) Expression of microtubule-associated proteins during early stages of neurite extension by brain neurons in defined medium. J Neurochem 47:1255-1261.

Dotti C, Banker G, Binder L (1987) The expression and distribution of the microtubule-associated protein Tau and microtubule-associated protein MAP-2 in hippocampal neurons in the rat in situ and in cell culture. Neuroscience 23:121-130.

Drubin D, Kirschner M (1986) Tau protein function in living cells. J Cell Biol 103:2739-2746.

Drubin D, Kirschner M, Feinstein S (1983) Microtubule-associated protein induction by nerve growth factor during neurite outgrowth in PC 12 cells. Cold Spring Harbor Symp Mol Neurobiol 40:343-355.

Drubin D, Feinstein S, Shooter E, Kirschner M (1985) Nerve growth factor induced neurite outgrowth in PC 12 cells involves the coordinate induction of microtubule assembly and assembly promoting factors. J Cell Biol 101:1799-1807.

Drubin D, Kobayashi S, Kellogg D, Kirschner M (1988) Regulation of microtubule protein levels during cellular morphogenesis in nerve growth factor-treated PC 12 cells. J Cell Biol 106:1583-1591.

Faivre-Baumann A, Rosembaum E, Puymirat J, Grouselle D, TixierVidal A (1981) Differentiation of fetal mouse hypothalamic cells in serum-free medium. Dev Neurosci 4:118-119.

Ferreira A, Caceres A (1989) The expression of acetylated microtubules during axonal and dendritic growth in cerebellar macroneurons which develop in vitro. Dev Brain Res 49:205-213.

Ferreira A, Busciglio J, Caceres A (1987) An immunocytochemical analysis of the ontogeny of the microtubule-associated protein MAP-2 and Tau in the nervous system of the rat. Dev Brain Res 34:9-31.

Ferreira A, Busciglio J, Caceres A (1989) Microtubule formation and neurite growth in cerebellar macroneurons which develop in vitro: evidence for the involvement of the microtubule-associated proteins MAP-1a, HMW-MAP2, and Tau. Dev Brain Res 49:215-228.

Ferreira A, Busciglio J, Landa C, Caceres A (1990) Ganglioside-enhanced neurite growth: evidence for a selective induction of high molecular weight MAP-2. J Neurosci 10:293-302.

Greene LA, Liem RKH, Shelanski ML (1983) Regulation of a high molecular weight microtubule-associated protein in $\mathrm{PC} 12$ cells by nerve growth factor. J Cell Biol 96:76-83.

Kirschner M, Mitchison T (1986) Beyond self assembly: from microtubules to morphogenesis. Cell 45:76-83.

Kosik KS, Finch EA (1987) MAP-2 and Tau segregate into axonal and dendritic domains after the elaboration of morphologically distinct neurites: an immunocytochemical study of cultured rat cerebrum. J Neurosci 7:3142-3153.

Loudes C, Faivre-Baumann A, Puymirat J, Tixier-Vidal A (1983) Effect of hormones on the development of mouse fetal hypothalamic neurons in vitro. Monogr Neural Sci 9:43-49.

Matus A (1988) Microtubule-associated proteins: their potential role in determining neuronal morphology. Annu Rev Neurosci 11:29-44.

Mitchison T, Kirschner MW (1988) Cytoskeletal dynamics and nerve growth. Neuron 1:761-772.

Moody SA, Quigg MS, Frankfurter A (1989) The development of the peripheral trigeminal system in the chick revealed by an isotypespecific anti $\beta$-tubulin monoclonal antibody. J Comp Neurol 279: $567-580$.

Piperno G, Le-Dizet M, Chang X (1987) Microtubules containing acetylated $\alpha$-tubulin in mammalian cells in culture. J Cell Biol 104: 289-302.

Reisert I, Han V, Lieth E, Toran-Allerand D, Pilgrim C, Lauder J (1987) Sex steroids promote neurite growth in mesencephalic tyrosine hydroxylase immunoreactive neurons in vitro. Int J Dev Neurosci 5: 91-98.

Stanley HF, Fink G (1986) Synthesis of specific brain proteins is influenced by testosterone at mRNA level in the neonatal rat. Brain Res 370:223-231.

Stanley H, Borthwick NN, Fink G (1986) Brain protein changes during development and sexual differentiation in the rat. Brain Res 370:215222.

Toran-Allerand D (1976a) Sex steroids and the development of the new-born mouse hypothalamus and preoptic area in vitro: new implications for sexual differentiation. Brain Res 106:407-412.

Toran-Allerand D (1976b) Golgi Cox modifications for the impregnation of whole mount preparations of organotypic cultures of CNS. Brain Res 118:293-298.

Toran-Allerand D (1981) Gonadal steroids and brain development: in vitro veritas? Trends Neurosci 4:1 18-121.

Toran-Allerand D (1983) Sex steroids and the development of newborn mouse hypothalamus in vitro. III. Effect of estrogen on dendritic differentiation. Dev Brain Res 7:97-101.

Toran-Allerand D (1985) Gonadal hormones and brain development: implications for the genesis of sexual differentiation. Ann NY Acad Sci 435:101-111.

Toran-Allerand D, Leland E, Pfeninger KH (1988) Estrogen and insulin synergism in neurite growth enhancement in vitro: mediation of steroids effects by interaction with growth factors? Dev Brain Res $41: 87-100$. 
Tucker R, Binder LI, Matus A (1988) Neuronal microtubule-assoc1ated proteins in the embryonic avian spinal cord. J Comp Neurol 271:44-55.

Uchibori M, Kawashima S (1985a) Effect of sex steroids on the growth of neuronal processes in neonatal rat hypothalamus, preoptic area and cerebral cortex in primary cultures. Int J Dev Neurosci 3:381388.

Uchibori M, Kawashima S (1985b) Stimulation of neuronal processes growth by estradiol $17 \beta$ in dissociated cells from fetal rat hypothalamus-preoptic area. Zool Sci 2:381-388. 